\title{
C1 anterior arch preservation in transnasal odontoidectomy using three-dimensional endoscope: A case report
}

\author{
Francesco Zenga, Nicola Marengo, Paolo Pacca, Giancarlo Pecorari¹, Alessandro Ducati \\ Department of Neurosciences, Molinette University Hospital, Via Cherasco 15, ${ }^{1}$ Department of Surgical Sciences, First ENT Division, Molinette University \\ Hospital, Via Genova 3, 10126 Torino, Italy \\ E-mail: Francesco Zenga - zengafra@hotmail.com; *Nicola Marengo - nicola.marengo@gmail.com; Paolo Pacca - paolopacca84@gmail.com; \\ Giancarlo Pecorari - giancarlo.pecorari@unito.it; Alessandro Ducati -aducati.nch@gmail.com \\ *Corresponding author
}

Received: 26 July 15 Accepted: 02 October 15 Published: 28 December 15

\begin{abstract}
Background: The transoral ventral corridor is the most common approach used to reach the craniovertebral junction (CVJ). Over the last decade, many case reports have demonstrated the transnasal corridor to the odontoid peg represents a practicable route to remove the tip of the odontoid process. The biomechanical consequences of the traditional odontoidectomy led to the necessity of a cervical spine stabilization. Preserving the inferior portion of the $\mathrm{C} 1$ anterior arch should prevent instability.

Case Description: This is the first report in which the technique to remove the tip of the odontoid while preserving the $\mathrm{C} 1$ anterior arch is described by means of a three-dimensional (3D) endoscope. A 53-year-old man underwent a transnasal 3D endoscopic approach because of a complex CVJ malformation. The upper-medial portion of the $\mathrm{C} 1$ anterior arch was removed preserving its continuity, and the odontoidectomy was performed. After surgery, a dynamic X-ray scan showed no difference in CVJ motility in comparison with the preoperative one.

Conclusions: The stereoscopic perception augmented the precision of the surgical gesture in the deep field. The importance of a 3D view relates to the depth of field, which a two-dimensional endoscopy cannot provide. This affects the preservation of the $\mathrm{C} 1$ anterior arch because of the presence of critical structures that are exposed to potential damage if not displayed.
\end{abstract}

Key Words: C1 anterior arch preservation, craniovertebral junction stability, three-dimensional endoscope, transnasal odontoidectomy

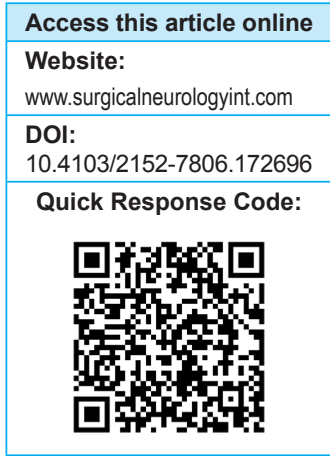

\section{BACKGROUND}

The transoral ventral microsurgical corridor is the most common ${ }^{[3,8,9,19,34]}$ approach used to reach the craniovertebral junction (CVJ) anomalies. Nevertheless, over the last decade, many cadaver studies and case reports $[2,6,7,17,18,30]$ demonstrated the transnasal corridor to the odontoid peg is a practicable route. In 2005, Kassam reported a technical case describing the feasibility of an odontoidectomy fully achieved through an endoscopic transnasal approach; Cappabianca described the same approach on a cadaver model in 2007.

This breakthrough actually depends on many significant technological improvements, such as the development of dedicated instruments, newly developed tools for a better visualization, and the even closer partnership

This is an open access article distributed under the terms of the Creative Commons Attribution-NonCommercial-ShareAlike 3.0 License, which allows others to remix, tweak, and build upon the work non-commercially, as long as the author is credited and the new creations are licensed under the identical terms.

For reprints contact: reprints@medknow.com

How to cite this article: Zenga F, Marengo N, Pacca P, Pecorari G, Ducati A. $\mathrm{Cl}$ anterior arch preservation in transnasal odontoidectomy using three-dimensional endoscope: A case report. Surg Neurol Int 2015;6:192. http://surgicalneurologyint.com/CI-anterior-arch-preservation-in-transnasalodontoidectomy-using-three-dimensional-endoscope:-A-case-report/ 
between neurosurgeons and ENT surgeons. Recently, the advantages of an ultrasonic bone curette to remove the bone during extended endoscopic approaches have been described. ${ }^{[4,39]}$ In addition, endoscopic neurosurgery could now benefit from the innovation given by three-dimensional (3D) view, ${ }^{[33]}$ in particular for midline skull base surgery. Moreover, several case reports and case series showed and highlighted promising and hopeful results in endoscopic transnasal odontoidectomy.

Thus, an anterior transnasal endoscopic decompression of lower brainstem and spinal cord may be achieved by removing the tip of the odontoid process. The instability given to the disruption of ventral atlantoaxial-occipital articular connections is still an issue, and patients require posterior fusion. Preserving the inferior portion of the $\mathrm{Cl}$ anterior arch should prevent instability ${ }^{[13,15]}$ and avoid a further posterior fixing procedure. The procedure to reach the odontoid while preserving the $\mathrm{Cl}$ arch could be difficult because of the lack of stereoscopic view, which is more important to reach deep-seated structures. This is the first report in which the technique to preserve the $\mathrm{Cl}$ anterior arch is described by means of a 3D endoscope.

\section{CASE DESCRIPTION}

A 53-year-old man with a long-lasting history of objective vertigo and neck pain accessed to emergency care because of a severe headache, disabling vertiginous crisis with falls, increasing neck pain also in lateral head movements and decline in health-related quality of life. Clinical examination showed hyperreflexia in lower limbs, diffuse burning paresthesia of the four limbs, bilateral Babinski sign, and downbeat nystagmus. Magnetic resonance imaging (MRI) and computed tomography (CT) scans showed a complex CVJ malformation with the basilar impression and radiological signs of myelopathy at the C2 level [Figure 1]. Furthermore, a dynamic cervical spine $\mathrm{X}$-ray proved that there was no instability in flexion and extension movements of the CVJ [Figure 2].

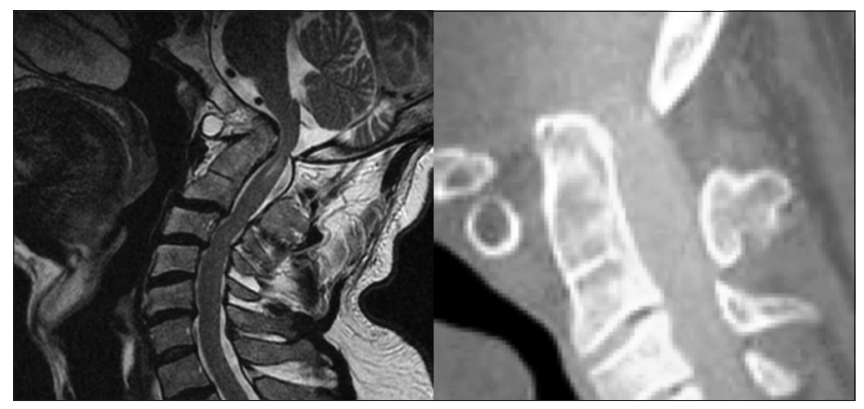

Figure I: Preoperative magnetic resonance imaging and computed tomography showing a complex craniovertebral junction malformation with basilar impression and radiological signs of myelopathy at $\mathrm{C} 2$ level
The patient underwent a transnasal image-guided fully 3D endoscopic approach [Figure 3]. Intraoperative neurophysiological monitoring was used: Somatosensory evoked potentials of the four limbs and motor evoked potentials. The technique to reach the CVJ has been described elsewhere. ${ }^{[17,18]}$

The lowest part of the clivus and the upper-medial portion of the $\mathrm{Cl}$ anterior arch were removed. After subperiosteal preparation of the $\mathrm{Cl}$ anterior arch, every effort was made to preserve the anterior arch integrity, drilling only its anterior-superior portion in the midline but keeping its continuity. At this stage, the partial drilling of the uppermost part of the odontoid peg was safely performed. After image guidance confirmation of the odontoid, a $3 \mathrm{~mm}$ coarse diamond burr was used to enter its anterior cortex. An ultrasonic bone curette was used to remove the tip of the odontoid, the base and the interface between the posterior cortex of the dens and the soft tissues covering the spinal dura. The decompression of the medulla and spinal cord was performed by using the neuronavigation system.

Furthermore, pulsatility of the dura during surgery confirmed the achievement of sufficient decompression.

After the procedure, the reverse $U$ mucosal nasopharingeal flap harvested at the beginning of surgery was reapproximated and fixed with fibrin glue. A Foley catheter was held in place for 2 days to compress the mucosal flap. No tracheostomy was needed, and the patient received food orally the day after surgery

Immediately after surgery, a dynamic X-ray scan was performed: The anterior atlas-dens interval (AADI), posterior atlas-dens interval (PADI), and $\mathrm{Cl}-\mathrm{C} 2$ total lateral overhang were measured as morphological criteria to determine the upper cervical spine

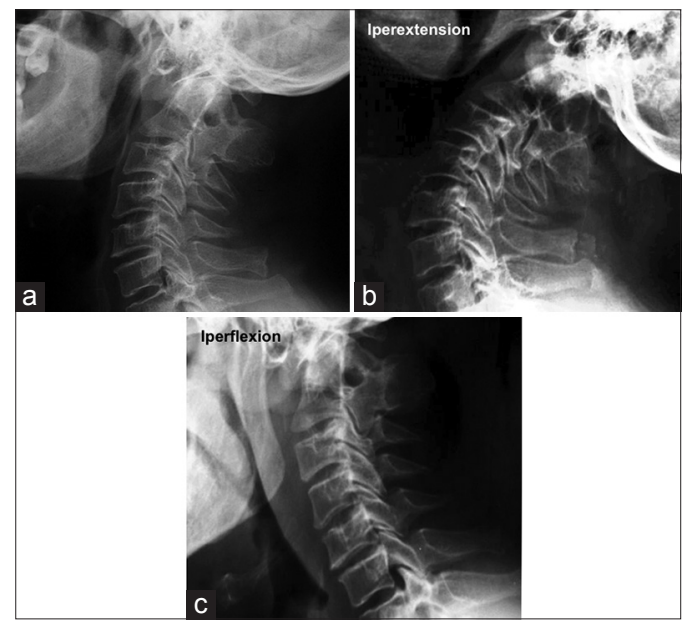

Figure 2: Preoperative dynamic cervical spine $X$-ray showing no instability of the craniovertebral junction ((a) static, (b) hyperextension, (c) hyperflexion) 


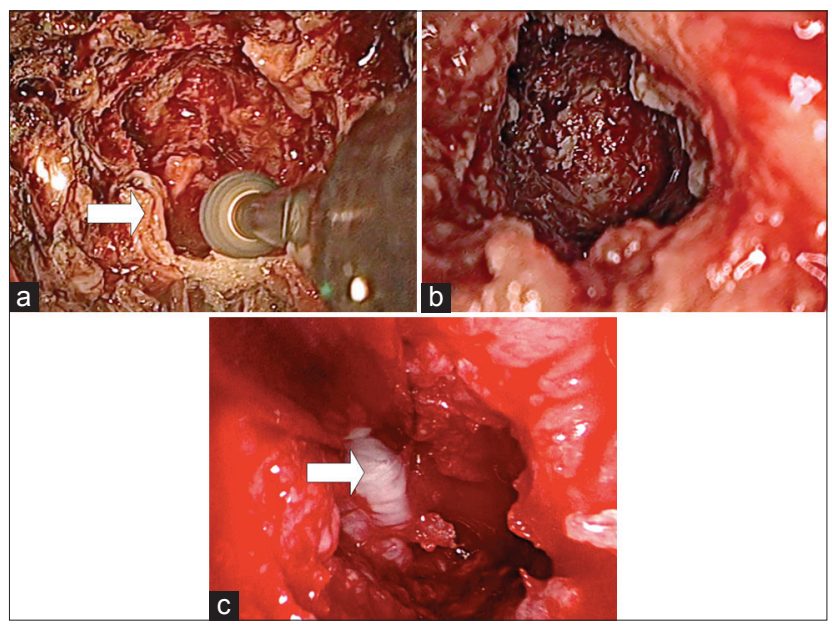

Figure 3: Intraoperative endoscopic views: (a) Cl anterior arch upper portion drilling; the arrow points out the residual lateral part of the arch (b) final endoscopic view after the odontoidectomy is completed showing the spinal cord dura just behind the drilled portion of the dens (c) the white arrow indicates the dura

stability. ${ }^{[12,35,37]}$ AADI and PADI remained stable after surgery, and the total Cl-C2 overhang was no more than $7 \mathrm{~mm}$, thus demonstrating no difference in CVJ motility compared with the preoperative radiographic pictures [Figure 4]. Therefore, we did not proceed to posterior cervical stabilization, postponing the eventual decision in light of the clinical status in the follow-up.

The postoperative course was uneventful, and the patient was discharged showing a significant improvement in paresthesia and the disappearance of nystagmus.

Postoperative dynamic CT and MRI confirmed complete CVJ decompression, and the patient underwent a nasal endoscopic follow-up 1 month after surgery and another one 6 months after surgery [Figure 5].

After an 18-month follow-up, the patient reported neither other vertiginous episodes, nor neck pain. Clinical examination showed normoreflexia in lower limbs, the absence of paresthesia of the four limbs, normal motor functions, bilateral negative cutaneous plantar reflex, and mild downbeat nystagmus.

At the 18-month re-evaluation, a new dynamic X-ray scan showed no difference in CVJ motility in comparison with the preoperative and immediately postoperative ones [Figure 6].

\section{CONCLUSIONS}

Anterior approaches to the CVJ have historically been open surgical procedures: The transoral-transpharyngeal approach has been the most used with or without the addition of extensive variations. Even though many recent technical improvements have been achieved, the transoral approach still presents some drawbacks. These include extended

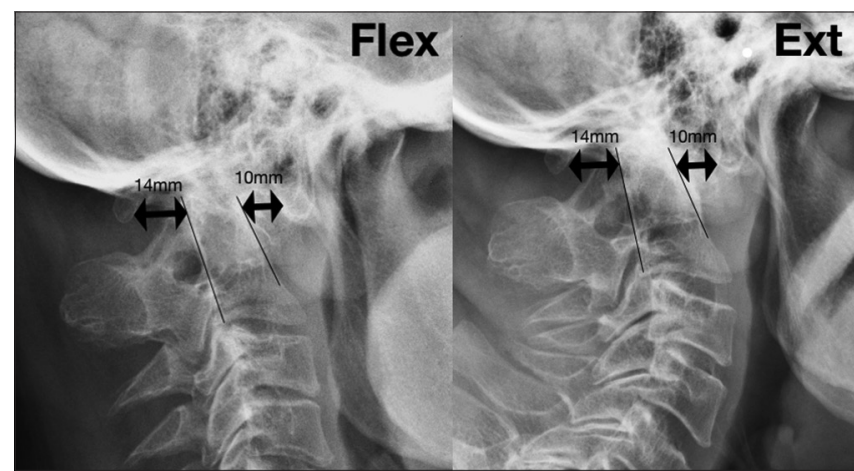

Figure 4: Dynamic X-ray with anterior atlas-dens interval and posterior atlas-dens interval performed before discharge showed no instability of the craniovertebral junction

postoperative intubation or tracheostomy, the need for nasogastric tube feeding, the risk of negative effects on phonation, potential contamination of the oropharyngeal wound, and consequent infective sequelae.

These include postoperative pulmonary complications, which were found to be $15.7 \%$ by Marda et al. in 2013 . Factors significantly associated with postoperative pulmonary complications consisted in a higher than II American Society of Anesthesiologists grade, preoperative lower cranial nerves palsy and respiratory involvement, length of surgery and intraoperative blood transfusion. In multivariate analysis, blood transfusion was found to be the sole contributing factor. The patients with postoperative pulmonary complications had significantly prolonged their stay in Intensive Care Unit and hospital. ${ }^{[24]}$

Tracheostomy may allow the prevention of postoperative respiratory complications and safeguard against airway obstruction from postoperative lingual edema. In 2007, Landeiro et al. reported no cases of preoperative tracheostomy; however, postoperative tracheostomy was required in 10 out of 38 cases due to the involvement of the lower cranial nerves and when a prolonged intubation was required in the postoperative period.

Moreover, they reported 3 cases of soft palate dehiscence, which required resuture and long-term enteral nutrition, 3 patients with pulmonary infection, 1 cerebrospinal fluid (CSF) leakage, and 1 death in the immediate postoperative period because of pulmonary embolism. ${ }^{[36]}$

The CSF leaks encountered when performing a transoral odontoidectomy potentially have devastating consequences, such as meningitis and related death. ${ }^{[21]}$

An incision of the soft palate or osteotomy of the hard palate has a high probability of complications such as dysphagia, nasal regurgitation and regurgitation with speech, and swallowing due to velopharyngeal insufficiency. ${ }^{[28]}$ 


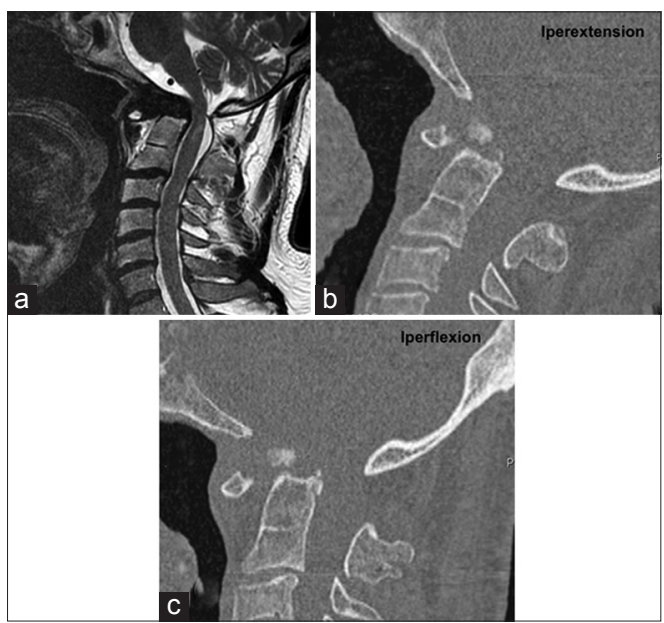

Figure 5: Postoperative dynamic computed tomography $(b, c)$ and magnetic resonance (a) imaging demonstrated the achievement of a good spinal cord decompression

In 2005, Kassam et al. first described an endoscopic endonasal approach for the resection of the odontoid tip and rheumatoid pannus in a 73-year-old woman with a posterior fixation. They have demonstrated the effectiveness of this anatomical pathway and the lower morbidity compared to the traditional transoral approach. Thereafter, other authors have successfully tested this approach. ${ }^{[1,27]}$ Before surgery, we have considered the socalled nasopalatine line (the K-line) that extends from the tip of the nasal cartilage to the upper cervical spine, with a fulcrum on the hard palate. This line, which always has to be evaluated in the preoperative planning, ${ }^{[23]}$ represents the caudal limit of craniocervical lesions that can be reached via endonasal endoscopic approach. Lesions above this line are accessible via this route. In 2007, Wolinsky et al. reported three odontoidectomy performed by an endoscopic transcervical approach: The significant attainment was the preservation of the pharyngeal mucosa with a fair decrease in contamination risk by bacterial flora. Nevertheless, the feasibility of this approach has been criticized because of the long distance to the target, its narrow and oblique working angle, the difficulty in reaching the contralateral side and performing it in highly kyphotic cervical spines. ${ }^{[10,26,29,38]}$ In 2009, Leng et al. described an endonasal endoscopic resection of an odontoid tip to decompress the cervicomedullary junction; in this case, a posterior occipital-cervical fixation was performed before the odontoidectomy since it had been planned to completely remove the anterior arch of $\mathrm{Cl}$ that results in biomechanical instability of the occipital-cervical junction. ${ }^{[22]}$

Dickman et al. studied and reported the biomechanical consequences of the traditional transoral odontoidectomy. The authors found significant increases in flexion, extension, and lateral bending after odontoidectomy. Flexion increased by $70.8 \%$, extension by $104 \%$, and lateral

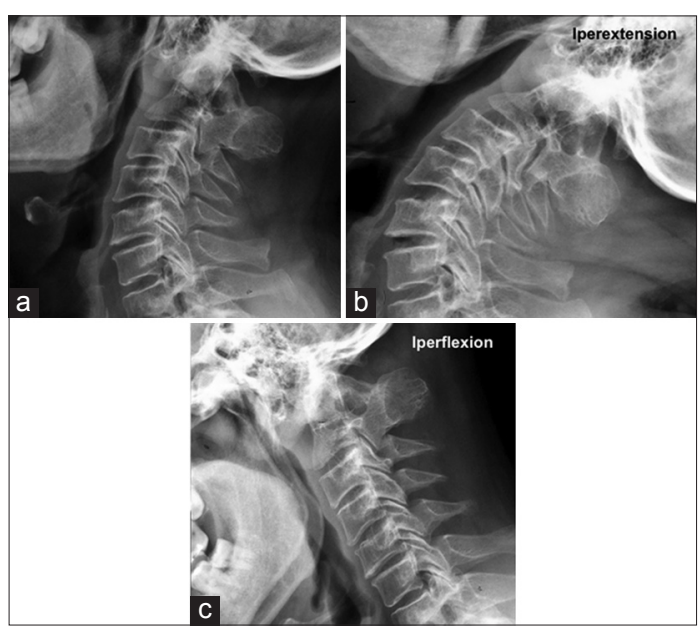

Figure 6: Static (a) and dynamic (b,c) X-ray 18 months after discharge confirming that there was no instability of the craniovertebral junction

bending by $95 \%$. The transoral odontoidectomy produces distinct alterations in motion and in force-deformation responses at $\mathrm{Cl}-\mathrm{C} 2$. The surgery results in prominent anteroposterior translation; increases angular range of motion during flexion, extension, and lateral bending. These biomechanical alterations are not surprising because transoral odontoidectomy profoundly alters the anatomy of the CVJ. ${ }^{[2,31,32]}$ During surgery, the primary stabilizing components are detached or removed, including the dens, the alar ligaments, and the transverse atlantal ligament. A great contribution to decrease the postoperative risk of spinal instability is the preservation of the anterior $\mathrm{Cl}$ arch. ${ }^{[20]}$ This could prevent the $\mathrm{Cl}$ lateral masses displacement caused by vertical loading forces. ${ }^{[15,29,36]}$ Thus, one of the most critical issue for the stability of the CVJ is the integrity of the $\mathrm{Cl}$ ring. Transection of the anterior $\mathrm{Cl}$ arch could bring to lateral masses displacement and subsequent cranial settling ${ }^{[11,14,16,36]}$ with possible increased risk of neurological sequelae. Therefore, whenever feasible, only a partial resection of the $\mathrm{Cl}$ anterior arch is recommended during an odontoidectomy. We considered safe to preserve the half-lower medial part of the arch to keep a solid continuity of the ring and to obtain a better access to the odontoid tip. If it is not possible to achieve an adequate decompression without transection of the $\mathrm{Cl}$ anterior arch, a posterior fixation may be required. Moreover, capsular ligaments, paraspinal muscle, tectorial membrane, anterior longitudinal ligament, and ligamentum flavum play the important role of second stabilizers, whose action can be negatively affected by the loss of integrity of the $\mathrm{Cl}$ ring.

Iacoangeli moved another step forward for the transnasal endoscopic approach describing 2 cases in 2012 and 2013. They reported that the preservation of the anterior arch of $\mathrm{Cl}$ could prevent instability of the occipital-cervical junction and avoid posterior settling. Every effort was 
made to preserve the anterior arch of the atlas or, if needed, to drill only its anterior-inferior portion around the midline, but still maintaining the continuity of the Cl ring.

Furthermore, reducing the classical two parts (anterior and posterior) of surgical procedures to only the anterior one would result in avoiding the toughest part of the procedures and having fewer morbidities for the patient, who would benefit from a faster postoperative recovery. Thus, preserving the rotational movement at $\mathrm{C} 0-\mathrm{C} 2$ segment and reducing the risk of a subaxial instability development.

In our case, the approach was performed using a 3D endoscope (Visionsense II Ltd., Petach Tikva, Israel) to preserve the integrity of the $\mathrm{Cl}$ anterior arch. The relevant importance of 3D view depends on the greater depth of field provided compared to that of a two-dimensional (2D) endoscope. As already demonstrated for laparoscopic surgery, the effectiveness of transnasal endoscopic surgical procedures has increased considerably with the introduction of 3D vision. Working in a 3D environment allows to be more selective, as well as during the nasal approach preserving the olfactory mucosa in order to reduce the rate of postoperative anosmia. In 2012, the group of Castelnuovo et al. described a case of transnasal resection of anterior skull base malignancy with a $3 \mathrm{D}$ endoscope. They reported that surgeons were able to recognize and manage anatomical structures, and to control bleeding easily thanks to the bimanual technique and $3 \mathrm{D}$ visualization. ${ }^{[5]}$

Probably the most fascinating potential of 3D vision is the ability to control the anatomical structures that are present but not usually and easily visible. This is of incalculable value for the preservation of the $\mathrm{Cl}$ anterior arch because of the presence of critical structures that are exposed to potential damage, if not properly displayed.

Moreover, recognizing the precise relation between ligaments and bony structures provides an excellent level of safety during the procedure. Therefore, 3D techniques certainly represent a great breakthrough in the endoscopic surgery of the anterior skull base. The addition of depth perception allows to overcome the limitations of $2 \mathrm{D}$, making the new 3D endoscopic system the ideal tool for a wide range of procedures.

Finally, the accuracy in the visualization of the anatomical structures and their relationships make 3D endoscope a versatile tool that needs a shorter learning curve if compared with the traditional 2D endoscope.

\section{Financial support and sponsorship}

Nil.

\section{Conflicts of interest}

There are no conflicts of interest.

\section{REFERENCES}

I. Agrawal A, Reyes PM. A novel technique of odontoidoplasty and $\mathrm{Cl}$ arch reconstruction: Anatomical and biomechanical basis. Neurosurgery 20 I I;68 I Suppl Operative: I03-I3.

2. Alfieri A, Jho HD, Tschabitscher M. Endoscopic endonasal approach to the ventral cranio-cervical junction: Anatomical study. Acta Neurochir (Wien) 2002; |44:219-25.

3. Blazier CJ, Hadley MN, Spetzler RF. The transoral surgical approach to craniovertebral pathology.J Neurosci Nurs 1986;18:57-62.

4. Cappabianca P, Cavallo LM, Esposito I, Barakat M, Esposito F. Bone removal with a new ultrasonic bone curette during endoscopic endonasal approach to the sellar-suprasellar area: Technical note. Neurosurgery 2010;66:EI I8.

5. Castelnuovo P, Battaglia P, Bignami M, Ferreli F, Turri-Zanoni M, Bernardini E, et al. Endoscopic transnasal resection of anterior skull base malignancy with a novel 3D endoscope and neuronavigation. Acta Otorhinolaryngol Ital 2012;32:I89-9I.

6. Cavallo LM, Cappabianca P, Messina A, Esposito F, Stella L, de Divitiis E, et al. The extended endoscopic endonasal approach to the clivus and cranio-vertebral junction: Anatomical study. Childs Nerv Syst 2007;23:665-7I.

7. Cavallo LM, Messina A, Cappabianca P, Esposito F, de Divitiis E, Gardner P, et al. Endoscopic endonasal surgery of the midline skull base: Anatomical study and clinical considerations. Neurosurg Focus 2005; 19:E2.

8. Crockard HA. The transoral approach to the base of the brain and upper cervical cord. Ann R Coll Surg Engl 1985;67:321-5.

9. Crockard HA. Transoral surgery: Some lessons learned. $\mathrm{Br} J$ Neurosurg 1995;9:283-93.

10. Dasenbrock HH, Clarke MJ, Bydon A, Sciubba DM, Witham TF, Gokaslan ZL, et al. Endoscopic image-guided transcervical odontoidectomy: Outcomes of 15 patients with basilar invagination. Neurosurgery 2012;70:351-9.

II. Dickman CA, Crawford NR, Brantley AG, Sonntag VK. Biomechanical effects of transoral odontoidectomy. Neurosurgery 1995;36: I I46-52.

12. Fielding JW, Cochran GV, Lawsing JF $3^{\text {rd }}$, Hohl M. Tears of the transverse ligament of the atlas. A clinical and biomechanical study. J Bone Joint Surg Am 1974;56:1683-9I.

13. Gladi M, lacoangeli M,Specchia N, Re M, Dobran M,Alvaro L, et al. Endoscopic transnasal odontoid resection to decompress the bulbo-medullary junction: A reliable anterior minimally invasive technique without posterior fusion. Eur Spine J 20 I3;2 I Suppl I:S55-60.

14. lacoangeli M, Di Rienzo A, Alvaro L, Scerrati M. Fully endoscopic endonasal anterior $\mathrm{Cl}$ arch reconstruction as a function preserving surgical option for unstable atlas fractures. Acta Neurochir (Wien) 20I2; I54:1825-6.

15. lacoangeli M, Gladi M, Alvaro L, Di Rienzo A, Specchia N, Scerrati M. Endoscopic endonasal odontoidectomy with anterior $\mathrm{Cl}$ arch preservation in elderly patients affected by rheumatoid arthritis. Spine J 20I3; 3:542-8.

16. Ito H, Neo M, Sakamoto T, Fujibayashi S, Yoshitomi H, Nakamura T. Subaxial subluxation after atlantoaxial transarticular screw fixation in rheumatoid patients. Eur Spine J 2009; 18:869-76.

17. Kassam AB, Abla A, Snyderman C, Carrau R, Spiro R. An endoscopic transnasal odontoidectomy to treat cervicomedullary compression with basilar invagination. Oper Tech Neurosurg 2005;8: 198-204.

18. KassamAB,Snyderman C, Gardner P, Carrau R,Spiro R.The expanded endonasal approach: A fully endoscopic transnasal approach and resection of the odontoid process:Technical case report. Neurosurgery 2005;57 I Suppl: E2I 3.

19. Kingdom TT, Nockels RP, Kaplan MJ. Transoral-transpharyngeal approach to the craniocervical junction. Otolaryngol Head Neck Surg 1995; I I 3:393-400.

20. Koller H, Resch H, Tauber M, Zenner J, Augat P, Penzkofer R, et al. A biomechanical rationale for $\mathrm{Cl}$-ring osteosynthesis as treatment for displaced Jefferson burst fractures with incompetency of the transverse atlantal ligament. Eur Spine J 2010;19:1288-98.

21. Landeiro JA, Boechat S, Christoph Dde H, Gonçalves MB, Castro ID, Lapenta MA, et al. Transoral approach to the craniovertebral junction. Arq Neuropsiquiatr 2007;65: I I66-7I.

22. Leng LZ, AnandVK, Hartl R, SchwartzTH. Endonasal endoscopic resection of an os odontoideum to decompress the cervicomedullary junction: A minimal access surgical technique. Spine (Phila Pa 1976) 2009;34:EI39-43.

23. Magrini S, Pasquini E, Mazzatenta D, Mascari C, Galassi E, Frank G. Endoscopic 
endonasal odontoidectomy in a patient affected by Down syndrome: Technical case report. Neurosurgery 2008;63:E373-4.

24. Marda M, Pandia MP, Rath GP, Bithal PK, Dash HH. Post-operative pulmonary complications in patients undergoing transoral odontoidectomy and posterior fixation for craniovertebral junction anomalies.J Anaesthesiol Clin Pharmacol 20I3;29:200-4.

25. McCabe CM, McLachlin SD, Bailey SI, Gurr KR, Bailey CS, Dunning CE. The effect of soft-tissue restraints after type II odontoid fractures in the elderly: A biomechanical study. Spine (Phila Pa 1976) 20I2;37:1030-5.

26. McGirt MJ, Attenello FJ, Sciubba DM, Gokaslan ZL, Wolinsky JP. Endoscopic transcervical odontoidectomy for pediatric basilar invagination and cranial settling. Report of 4 cases. J Neurosurg Pediatr 2008; I:337-42.

27. Messina A, Bruno MC, Decq P, Coste A, Cavallo LM, de Divittis E, et al. Pure endoscopic endonasal odontoidectomy: Anatomical study. Neurosurg Rev 2007;30:189-94

28. Mummaneni PV, Haid RW. Transoral odontoidectomy. Neurosurgery 2005;56:1045-50.

29. Naderi S, Crawford NR, Melton MS, SonntagVK, Dickman CA. Biomechanical analysis of cranial settling after transoral odontoidectomy. Neurosurg Focus 1999;6:e7.

30. Nayak JV, Gardner PA, Vescan AD, Carrau RL, Kassam AB, Snyderman CH. Experience with the expanded endonasal approach for resection of the odontoid process in rheumatoid disease.Am J Rhinol 2007;21:60 I-6.
31. Panjabi MM.The stabilizing system of the spine. Part I. Function, dysfunction, adaptation, and enhancement. J Spinal Disord 1992;5:383-9.

32. Puttlitz CM, Goel VK, Clark CR, Traynelis VC, Scifert JL, Grosland NM. Biomechanical rationale for the pathology of rheumatoid arthritis in the craniovertebral junction. Spine (Phila Pa I976) 2000;25:I607-I6.

33. Roth J, Singh A, Nyquist G, Fraser JF, Bernardo A, Anand VK, et al. Three-dimensional and 2-dimensional endoscopic exposure of midline cranial base targets using expanded endonasal and transcranial approaches. Neurosurgery 2009;65: I I I6-28.

34. Shaha AR, Johnson R, Miller J, Milhorat T.Transoral-transpharyngeal approach to the upper cervical vertebrae. Am J Surg 1993; I66:336-40.

35. Spence KF Jr, Decker S, Sell KW. Bursting atlantal fracture associated with rupture of the transverse ligament. J Bone Joint Surg Am 1970;52:543-9.

36. Steinmetz MP, Mroz TE, Benzel EC. Craniovertebral junction: Biomechanical considerations. Neurosurgery 2010;66 3 Suppl: 7-12.

37. White AA, Panjabi MM. Clinical Biomechanics of the Spine. Philadelphia: Lippincott; 1990.

38. Wolinsky JP, Sciubba DM, Suk I, Gokaslan ZL. Endoscopic image-guided odontoidectomy for decompression of basilar invagination via a standard anterior cervical approach.Technical note.J Neurosurg Spine 2007;6: I84-91.

39. Zenga F, Villaret AB, Fontanella MM, Nicolai P. Endoscopic transnasal odontoidectomy using ultrasonic bone curette:Technical case report. Neurol India 20|3;6I:69-72. 